electrical resistance-was first discovered by the Dutch physicist Kamerlingh Onnes in 1911. But it was not until the development of high-field superconductors and alloys capable of handling very large currents that it became clear that industrial development of superconductivity was worthwhile.

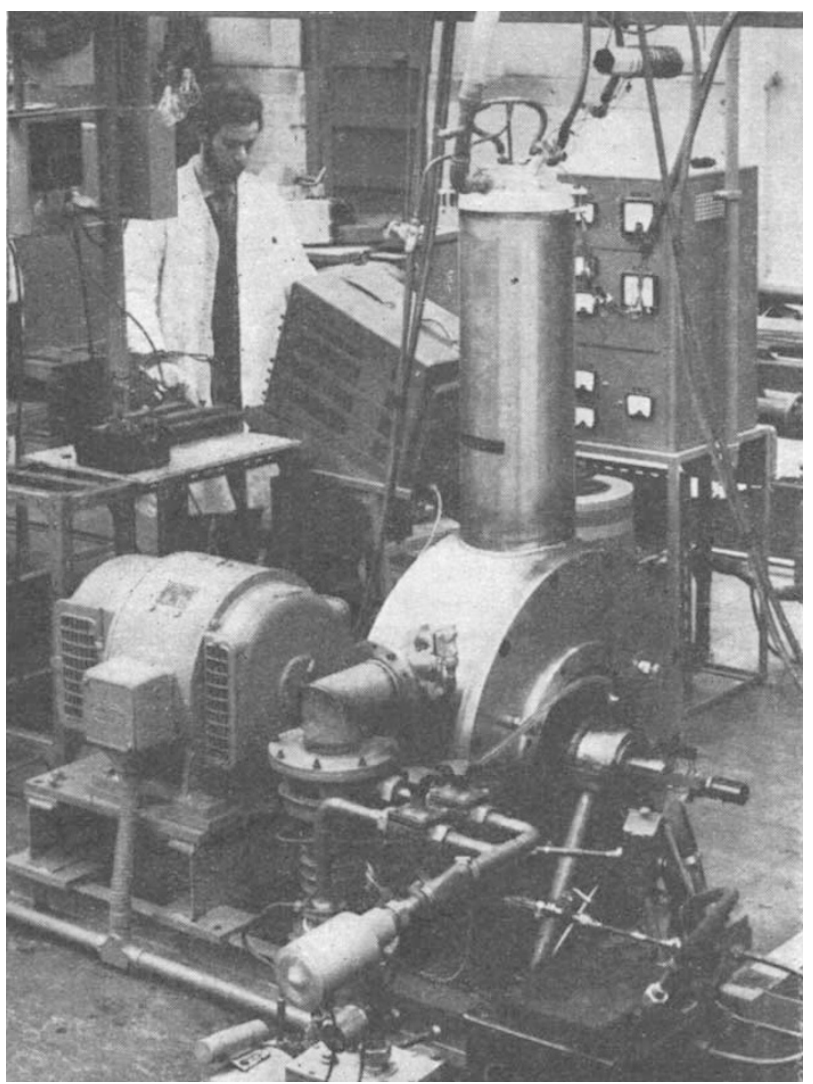

A 50 h.p. superconducting motor developed at International Research and Development Ltd. in Newcastle.

The project at IRD began as a feasibility study for the Ministry of Defence, and showed that a large superconducting motor was possible. Initially a small motor of only 2 h.p. was envisaged, but after some work it was realized that it would be possible to make a much more ambitious motor, producing 50 h.p. and running at 2,000 r.p.m. When this was built, further financial support was sought from the National Research Development Corporation, which appointed a working party to examine the proposal. Although the working party recommended that a 1,000 h.p. motor should first be constructed, NRDC decided to be bold and to go straight to a motor of 3,000 h.p. and 200 r.p.m., the size at which it is estimated superconducting motors will break even on cost with conventional motors. The large motor is to be tested at Fawley power station, by agreement with the Central Electricity Generating Board. The water cooling pumps at Fawley are rated at 3,250 h.p. and 200 r.p.m., designed to be driven by a conventional a.c. motor through reduction gearing. Although the conventional motor runs at 900 r.p.m. to produce the necessary power, the superconducting motor will be able to do it at 200 r.p.m. The stator for the Fawley motor will use a fully stabilized titanium/copper composite super- conductor, cooled by a closed circuit helium refrigerator supplied by British Oxygen Cryoproducts Division. The rotor, which will not be superconducting, will be water cooled.

As well as using superconductivity, the engineers at Newcastle, led by Mr A. D. Appleton, have improved the design of the simple homopolar motor, first devised by Faraday. This type of motor, although very simple in design, has been slow to develop because it calls for a high current and low voltage supply. At IRD a system has been devised which uses a segmented disk - the rotor of the homopolar system-to overcome this difficulty, and $\mathbf{M r}$ Appleton thinks that the new design may have potential uses in electric transport, though not in a superconducting form. Homopolar motors would have the distinct advantage that they could be used to regenerate the batteries while braking the vehicle.

The other advantage of the superconducting motor is a remarkable saving in weight. IRD estimates that with an 8,000 h.p. motor the saving in cost would be $£ 70,000$ ( $£ 150,000$ instead of $£ 220,000$ ) and the superconducting version would weigh only one-ninth as much as the conventional motor. These advantages, IRD believes, will soon make the adoption of superconducting motors inevitable.

\section{Cutting off Europe's Nose}

Technological progress in Europe is being hampered by Britain's exclusion from the EEC. In an address to the Council of Europe on January 29, Mr Anthony Wedgwood Benn, Minister of Technology, reaffirmed the British Government's belief that technical collaboration "within an enlarged common market" is the only way Europe can hope to catch up and keep pace with the United States. Industrial and economic integration will be necessary for this, and Europeanbased international companies must be created if industry is to operate on an adequate scale.

Despite the French veto, which"weakens European economic power in the face of transatlantic pressures", Britain is determined to pursue her policy of collabora. tion with the EEC and is prepared to consult with any country if mutual benefit will result. $\mathrm{Mr}$ Wedgwood Benn said that the decision to devalue the pound, which was taken in the hope of strengthening the economy, has turned Britain "decisively and irrevocably in the direction of Europe". Rationalization of industry within the country has been going on, notably in vehicle manufacturing and the electrical industries, and research projects are being examined for possible areas of collaboration with European countries. Computers, electronics and civil applications of atomic energy are three that have been mentioned already, but there are likely to be many more.

British collaboration is not, however, likely to be limited to Europe. Contact with the United States will be continued, and the technologioal agreements that have been signed with Poland, Hungary, Rumania and the Soviet Union will mean that planning techniques and long-term research will be discussed. $\mathrm{Mr}$ Wedgwood Benn stated his belief that "technological collaboration cannot come to full fruition except within the confines of a single industrial and trading market", and, although Britain's entry into the Common Market has been delayed, it is not too soon for a 
start to be made on collaboration in such fields as industrial standards, company law and patents which the Council of Europe has begun to examine. The European Institute of Technology proposed by the Prime Minister in November was described as an "organization that would provide an independent centre of analysis available to governments and industries on industrial structures, problems and future developments". It would provide a forum for technological cxchanges, and by working in close collabora. tion with the EEC commission it could "play a major role in accelerating the achievement of a European technological community-a community which is essential if Europe's potentials are to be realized". But those who hoped that Mr Benn would finally disclose exactly what is in the Prime Minister's mind were disappointod. The European Institute of Technology remains a nebulous idea, splendid for injecting life into otherwise familiar speeches, but not apparently the subject of much serious study.

\section{Unequal Trade}

WI'H the worsening of relations between rich and poor countries as a result of wars in the Middle East and in Vietnam and racial tension in many countries, the meeting of the United Nations Conference on Trade and Development (UNCTAD) which is taking place in New Delhi will not be all plain sailing. The last meeting in Geneva in 1964 was an acknowledged flop, and hopes for the New Delhi meeting are not high. Too many countries, Britain included, have gone to the meeting without a clear policy.

UNCTAD-defined in the most recent annual review of the Overseas Development Institute (ODI, 12s.6d.) as "a forum for redressing the balance of the world's economic system in favour of the developing countries" - has not been a triumphant success in the past few years. Although one of its aims is to increase the production and value of commodities on which most developing countries rely, the price of commodities continues to fall. Increases in production or in productivity tend inevitably to be reflected by a decline in the prices paid for the commodities, so that the processes by which developed countries advance themselves tend to do the opposite for underdeveloped countries. UNCTAD also cherishes a hope of establishing aid to developing countries at the rate of 1 per cent of the GNP of developed countries, and of promoting tourism and regional co-operation between developing countries. But the chances of increasing aid at the moment are slim indeed-the British aid programme is to be fixed at the present ceiling of $£ 205$ million per year, despite devaluation, which means that the real value of the aid which Britain dispenses has fallen by between 8 and 11 per cent. This has happened after an actual cut of $£ 20$ million announced at the end of 1966 , so that the value of British aid to developing countries has fallen steadily for the past two years. In the circumstances, it would perhaps have been unreasonable to expect anything else, but it is hard for developing countries to feel that Britain's economic difficulties, alarming as they are, are anything like as serious as their own.

The annual review from the ODI suggests ways in which developing countries can make the best of a bad situation. It would not be helpful, the report argues, if the developing countries use the present UNCTAD meeting to attempt to force concessions from developed countries. UNCTAD, the authors of the report say, must work through consensus-if the proceedings are based on bargaining from strength, it will be impossible to get the system changed for the simple reason that bargaining from strength has produced the very system which is under attack. The UNCTAD secretariat, headed by Dr Rául Prebish, has prepared a detailed analysis of the present situation, together with a series of proposals for action, but these have been treated with scepticism by some of the developed countries. The ODI report suggests that detailed argument about the way the case has been presented should not be allowed to obscure the basic issue-that the present system for operating world trade is biased against the developing countries. UNCTAD, the report concludes, must devote itself to changing the economic system, not to trying to secure concessions within the existing system.

Whether the developing countries accept this timely advice remains to be seen. There is little doubt, however, that without a new stimulus the world aid programme runs the risk of coming to a halt through political apathy in the developed countries. This is depressing, and in this context the occasional success stories are very refreshing. Pakistan and Kenya are likely to be quoted frequently at the UNCTAD meeting as examples of what can be done.

\section{Reducing the Risks}

THE opening of the advanced Nuffield Transplantation Surgery Unit on January 31 by Sir Peter Medawar marks an important step forward in this extremely complex field. The Nuffield Foundation provided $£ 230,000$ towards the cost of the unit, which is at the Western General Hospital in Edinburgh.

According to Professor M. F. A. Woodruff, who is the director, the new unit has been designed for the treatment of patients who run a particular risk of infection because of having received immuno-suppressive agents. Three main categorics of patients will be admitted; first, those patients receiving organ transplants and who are receiving immuno-suppressive drugs; second, patients with auto-immune diseases also receiving these drugs; and, third, certain types of cancer patients who have reduced resistance to infectious agents. The unit will, however, also be available to patients who have been accidentally exposed to radiation.

There are six patient rooms and two operating theatres in the unit. These work on a complicated system of ventilation with sterilized air under pressure which will prevent any cross-infection. All materials entering the unit will be sterile and wrapped, and communication between patients and visitors will be through glass and using microphones. The first patients will be those receiving kidney grafts.

\section{Waiting, Not Yet Seeing}

THE mceting last week in Geneva of the Council of the European Molecular Biology Organization (EMBO) seems to have been a mixed success. The proposal for a central laboratory was presented by EMBO but not formally discussed-that will not happen until 